\section{Congratulatory Comment}

Check for updates

\title{
Congratulatory commentary from Consortium of Universities for Global Health
}

\section{Keith Martin}

Executive Director, Consortium of Universities for Global Health (CUGH)

(c) 2019 Korean Society of Global Health. This is an Open Access article distributed under the terms of the Creative Commons Attribution Non-Commercial License (https:// creativecommons.org/licenses/by-nc/4.0/) which permits unrestricted non-commercial use, distribution, and reproduction in any medium, provided the original work is properly cited.
The Journal of Global Health Science (JHGS) is a welcome and much needed platform to share high quality, multidisciplinary science to impact the broad challenges we face. Its willingness to cover a wide range of biomedical and non-biomedical disciplines and be open to different types of submissions will be warmly embraced by the global health, development and policy communities.

Journal's expressed interest to showcase research and commentaries that address the most important neglected threats to human well-being including: noncommunicable diseases, inequality, neglected tropical diseases and more will make it a sound reference for governments, communities and individuals seeking to affect change. It is inspiring that the Journal has explicitly committed to addressing the needs of the poorest and most vulnerable be they in low, middle-income or high-income countries.

Global health has been a leader in looking at the broader inputs that affect human well-being including those that threaten our planet's health. The Journal will share papers on how we can achieve a sustainable relationship with Earths ability to generate the ecosystem services we rely on for life. But the editors recognize that this is not enough. Knowledge must be translated into policies that are then scaled up in the sustainable manner. To achieve this more researchers must become public scientists to engage governments and the public to implement what we already know can address the threats before us.

The Consortium of Universities for Global Health (www.cugh.org) looks forward to working with Dr. Juhwan Oh and the editorial board of JGHS to advance our common mission to improve the well-being of people and the health of our planet. Chukhahmnida! 